\title{
Recent Developments on Domino Metathesis Reactions in India
}

\author{
Rahul S. Nandurdikar and Krishna P. Kaliappan*
}

\begin{abstract}
This review summarizes research work carried out in India on domino metathesis reactions using ruthenium-carbene complexes. This reaction has been widely used by synthetic chemists in India for the synthesis of polycyclic systems and complex molecular architectures.
\end{abstract}

Keywords: Domino reactions · Enyne metathesis · IMDA - Metathesis reactions $\cdot$ RCM
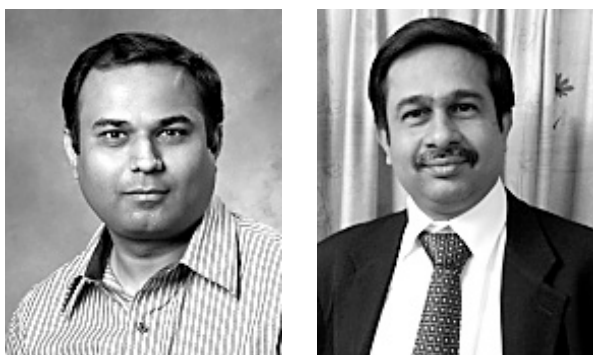

Dr. Rahul S. Nandurdikar (left) received his Ph.D. under supervision of Prof. Krishna P. Kaliappan from IIT-Bombay, Mumbai (May 2006). He completed his post-doctoral research work with Prof. Andrea Vasella (ETH Zurich, Switzerland) in Aug 2007. He moved to NIH/NCIFrederick, USA for post-doctoral research with Dr. Larry Keefer in the area of nitric oxide and nitroxyl prodrugs. Since Jan 2012, he is working in a Pharma company in India as a Research Scientist.

Prof. Dr. Krishna P. Kaliappan (right) received his M.Sc. (organic chemistry) in 1990, from Madurai Kamaraj University and later obtained his Ph.D. in synthetic organic chemistry from Indian Institute of Science, Bangalore in 1997. Subsequently he worked as a postdoctoral fellow at University of Geneva and Duke University prior to joining IIT Bombay in 2001 where he is a full professor since 2009 . His research interests include developing new strategies for synthesis of biologically active natural products and natural product like molecules. He is the recipient of B.M. Birla Science Prize (2006), Swarnajayanti Fellowship in Chemical Sciences (2007) from DST and CRSI Bronze Medal. He also received the Excellence in Teaching Award from IIT Bombay for the year 2011.

${ }^{\star}$ Correspondence: Prof. K. P. Kaliappan Department of Chemistry Indian Institute of Technology Bombay Powai, Mumbai 400076, India E-mail:kpk@chem.iitb.ac.in

\section{Introduction}

The ruthenium-carbene catalyzed 'olefin metathesis' reaction is one of the most important methods that has been extensively used for the formation of carbon-carbon bonds in organic synthesis in recent times. The ruthenium carbene complexes $^{[1]} \mathbf{1}$ and $\mathbf{2}$ developed by Grubbs and co-workers and recyclable phosphinefree ruthenium complex $3^{[2]}$ are the three catalysts which have been most commonly and successfully used in metathesis (Fig. 1). The olefin metathesis reactions are of several types, but the significant ones are: i) enyne metathesis, ${ }^{[3]}$ ii) ring closing metathesis (RCM) ${ }^{[4]}$ and iii) ring opening metathesis (ROM). These three reactions have emerged as vital tools for synthetic chemists due to their ease of operation, high yields and more importantly commercial availability of the catalysts.

Among these reactions, enyne metath- esis, an atom economy reaction, is an extremely powerful method for the construction of synthetically valuable 1,3-dienes. This reaction can be further divided into two types: (a) intramolecular enyne metathesis (Scheme 1a) and (b) inter-molecular or cross-enyne metathesis (Scheme 1b). Both forms of the reactions have found applications in total syntheses ${ }^{[3]}$ of many natural and unnatural products.

The RCM reaction involves cyclization of double bonds with evolution of ethylene as a by-product as shown in Scheme 2 . This reaction has been successfully used as a key step in the synthesis of a number of natural products. ${ }^{[4]} \mathrm{A}$ ROM reaction, which is the reverse of RCM reaction, also has found several interesting applications in synthesis of natural and natural product like molecules.

A consecutive combination of multiple metathesis reactions utilizing the same catalyst could lead to complex molecular ar-

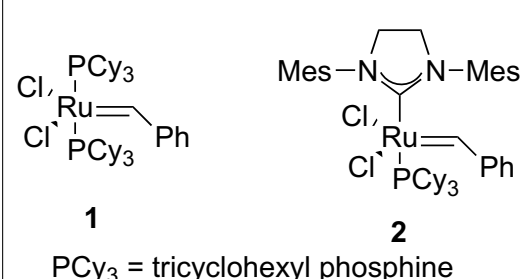

$\mathrm{PCy}_{3}=$ tricyclohexyl phosphine

Mes $=2,4,6$ (trimethyl) phenyl
Fig. 1. Structures of ruthenium carbene catalysts.

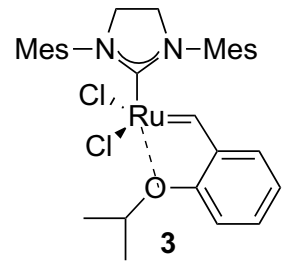

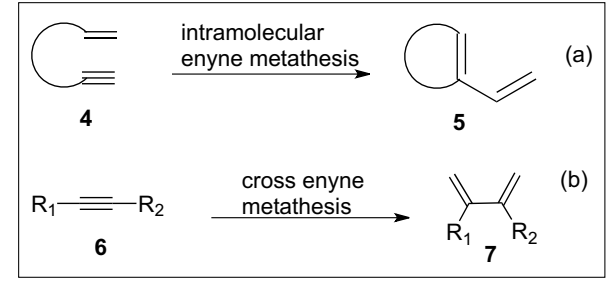

Scheme 1. (a) Representation of intramolecular enyne metathesis reaction. (b) Representation of cross-enyne metathesis or intermolecular enyne metathesis reaction.

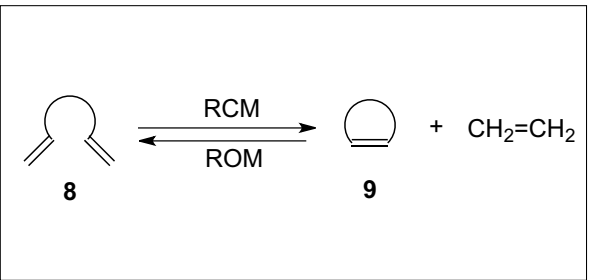

Scheme 2. Representation of RCM and ROM reactions. 


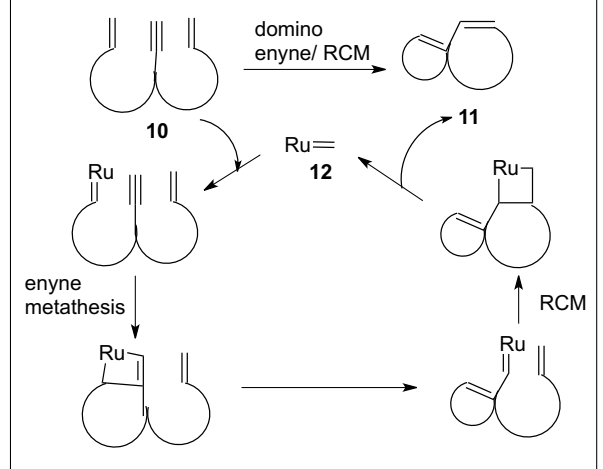

Scheme 3. Representation of a typical domino enyne/RCM reaction and its mechanism.

chitecture with a reduced number of steps. ${ }^{[5]}$ For example, a typical domino enyne metathesis followed by RCM is shown in Scheme 3.[6] The mechanism involves an active ruthenium-carbene $\mathbf{1 2}$ which initiates an enyne metathesis reaction followed by a RCM reaction through a series of [2+2] cycloaddition and cycloreversion processes as shown in Scheme 3. Such domino metatheses have been successfully exploited in the syntheses of several complex molecules and synthetic chemists from India have also significantly contributed in this area. This review will highlight some of the work done in India in the area of domino metathesis.

\section{Domino Enyne/RCM Reaction}

A domino enyne/RCM reaction typically involves an intramolecular enyne metathesis followed by a RCM to form a polycyclic system. Kaliappan et al. have reported a tandem metathesis sequence to build the core structure of angular dioxatriquinanes. ${ }^{[7]}$ Dioxatriquinanes are siblings of triquinane natural products having three fused five-membered rings. Depending on the fusion pattern they could be broadly classified into three types, namely, propellanes, linear and angular triquinanes. They are usually isolated either from plants or from marine sources and occasionally have microbial origin. The oxa- and dioxa-triquinanes bear one and two dihydro-furan moieties, respec-

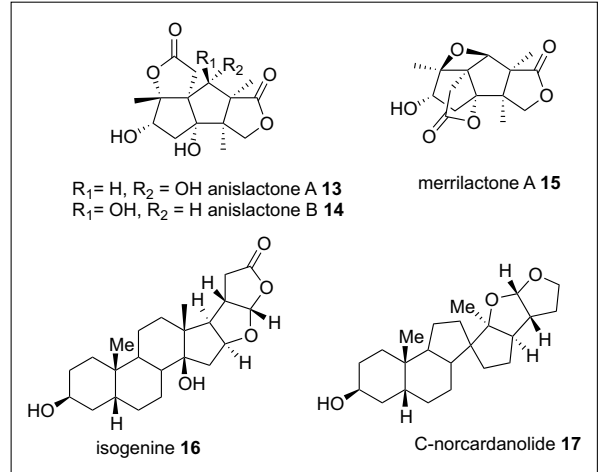

Fig. 2. Structures of oxa- and dioxa-triquinanes natural products.

tively, either in linear or angular fashion. Structures of biologically important oxaand dioxa-triquinanes like anislactone $\mathrm{A}$ (13) and B (14), ${ }^{[8]}$ merrilactone A (15), ${ }^{[9]}$ isogenine (16) ${ }^{[10]}$ and C-norcardanolide (17) ${ }^{[11]}$ are shown in Fig. 2.

Kaliappan's synthesis of these dioxatriquinanes started from readily available glucose-derived ketone $\mathbf{1 8}$ which was transformed into dienyne $\mathbf{1 9}$ as shown in Scheme 4. This dienyne was then sub- jected to the key tandem reaction using Grubbs' catalysts $\mathbf{1}$ and 2. However, all the attempts at the cascade reaction led to formation of only the enyne metathesis product 20, and failed to undergo the expected subsequent RCM to form 21. ${ }^{\text {[7] }}$ To circumvent this problem, the acetonide protection was removed by treatment with conc. $\mathrm{HCl}$ in $\mathrm{MeOH}$, and the two separable anomers were subsequently transformed into their acetates, and TBS-ethers (t-butyl dimethyl silyl ether). The key domino reaction was then performed on all the acetates, TBSethers and unprotected alcohols to furnish the core structure of dioxatriquinanes with varying reaction yields (Scheme 5 and Table 1).[12] Thus, this work indirectly proved that the acetonide protection hindered the RCM reaction after initial enyne metathesis. Furthermore, feasibility of this tandem reaction has been demonstrated on several substrates including unprotected alcohols.

In 2005, the same group also extended this strategy for the synthesis of the core structure of guaianolides and thapsigargins. ${ }^{[13]}$ Guaianolides are sesquiterpene lactones characterized by 5,7,5-fused sys-

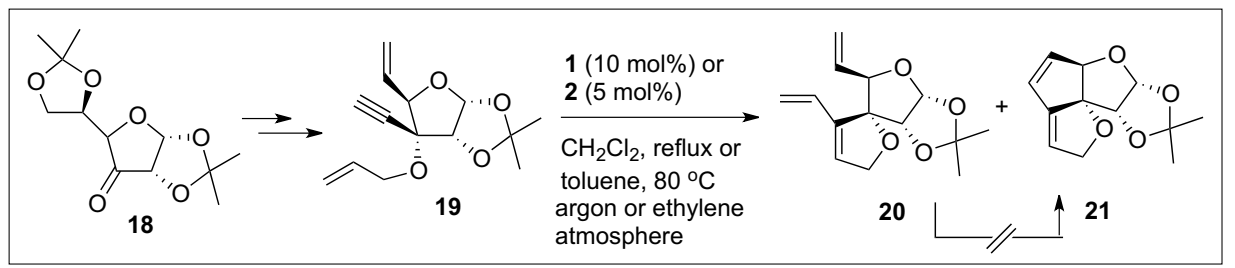

Scheme 4. Attempted tandem reaction on dienyne 19.

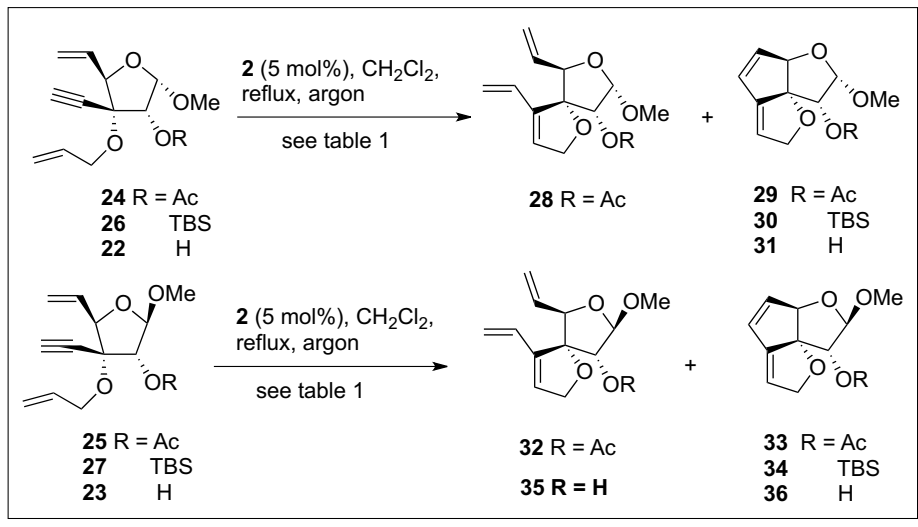

Scheme 5. Tandem enyne metathesis/ RCM.

Table 1. Isolated yields for the tandem reaction of dienynes 22-27.

\begin{tabular}{|c|c|c|c|c|}
\hline Entry & Substrate & Reflux time & \multicolumn{2}{|c|}{$\begin{array}{c}\text { Product ratio [\%] } \\
\text { Enyne product : Tandem product }\end{array}$} \\
\hline 1. & $\mathbf{2 4}(\alpha$-anomer $)$ & $36 \mathrm{~h}$ & 40 & 58 \\
\hline 2. & $\mathbf{2 5}$ ( $\beta$-anomer $)$ & $36 \mathrm{~h}$ & 36 & 60 \\
\hline 3. & $\mathbf{2 6}(\alpha$-anomer $)$ & $18 \mathrm{~h}$ & Not isolated & 76 \\
\hline 4. & $\mathbf{2 7}(\beta$-anomer $)$ & $18 \mathrm{~h}$ & Not isolated & 68 \\
\hline 5. & $\mathbf{2 2}(\alpha$-anomer $)$ & $48 \mathrm{~h}$ & Not isolated & 56 \\
\hline 6. & $\mathbf{2 3}(\beta$-anomer $)$ & $48 \mathrm{~h}$ & 63 & 18 \\
\hline
\end{tabular}

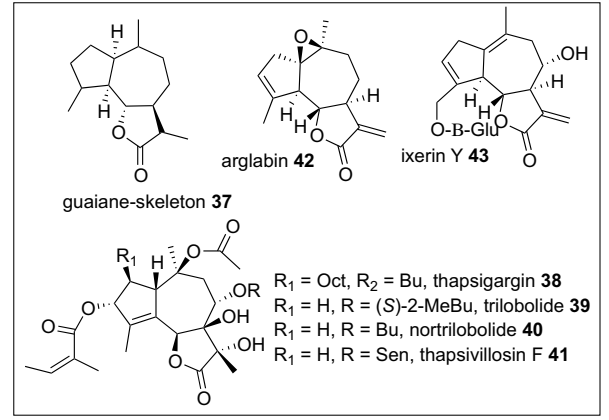

Fig. 3. Structures of biologically active thapsigargins and other guaianolides. 


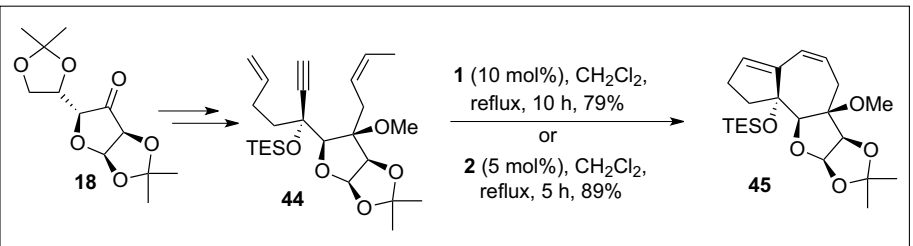

Scheme 6. Synthesis of thapsigargin core structure 45.

tem, and a typical guaiane-skeleton 37 with adequate relative stereochemistry is shown in Fig. 3.[14] Thapsigargins 38-41, belonging to this family, have a densely oxygenated tricyclic scaffold with more than seven stereogenic centers and are functionalized with an array of different acyl groups. ${ }^{[15]}$ They are known to be potent histamine liberators and selective inhibitors of sarcoendoplasmic reticulum $\mathrm{Ca}^{2+}$ ATP dependent pumps (SERCAs). Two more guaianolides, arglabin (42) ${ }^{[16]}$ and ixerin Y (43) ${ }^{[17]}$ having the 5,7,5-tricyclic ring system, exhibit strong activities against breast, colon, ovarian, and lung cancers.

The precursor dienyne $\mathbf{4 4}$, required for the key tandem reaction, was synthesized starting from ketone $\mathbf{1 8}^{[13]}$ in a few steps. Unlike in the synthesis of dioxatriquinanes, the dienyne $\mathbf{4 4}$ consisted of a terminal olefin and an internal olefin. Having one sterically hindered internal olefin would secure one way of tandem process, wherein the terminal olefin would take part in the enyne metathesis and the internal one in the consecutive RCM reaction. This would lead to the required 5,7,5 skeleton. The dienyne 44 under high dilution conditions with Grubbs' catalyst 1 underwent a smooth tandem enyne/RCM reaction to afford the 5,7,5-fused ring system as the only isolable product $\mathbf{4 5}$ in good yield (79\%). The use of the more reactive Grubbs' second generation catalyst $\mathbf{2}$ not only improved the yield to $89 \%$ but also reduced the reaction time significantly (Scheme 6).

In 2007, Krishna et al. reported synthe$\operatorname{sis}^{[18]}$ of the originally proposed structure of ilexlactone (46) isolated from Ilex aquifolium. The synthesis for the proposed target began with L-malic acid derived allylic alcohol 47, which was then transformed into dienyne 48 (Scheme 7). This dienyne 48 had an electron-rich and an electrondeficient alkene which ensured the predominant pathway for the initial enyne metathesis, followed by RCM to afford 49. The spectral data of the synthesized natural product, after the removal of MOM group, did not match with that of natural ilexlactone, thus revealing that the originally proposed structure for ilexlactone was incorrect. ${ }^{[18]}$ Hence, they also synthesized all other possible isomers for the natural product using the domino metathesis reaction protocol and unfortunately none of them were found to be correct.

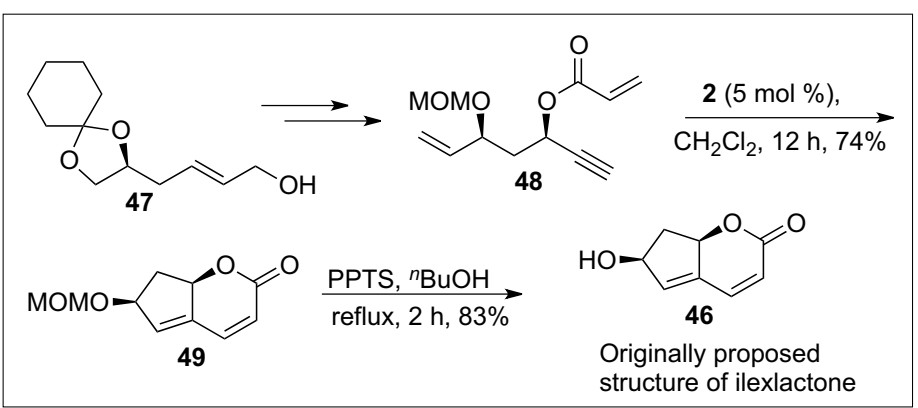

Scheme 7. Synthesis of the originally proposed structure of ilexlactone (46).

\section{Domino Cross-enyne/RCM Reaction}

Similar to domino intramolecular enyne metathesis followed by RCM, its intermolecular variant has also been extensively used in organic synthesis. In this type of domino protocol, a cross-enyne metathesis is followed by a $\mathrm{RCM}$ reaction in the same reaction pot. Kaliappan and co-workers have utilized this protocol for the synthesis of 4-methylene-2-cyclohexenone derivatives. ${ }^{[19]}$ 4-Methylene-2-cyclohexenone and 4-methylene-2-cyclohexenol (50b) are unique substructures present in natural products such as otteliones A (51) and B (52), loloanolides B (53), and 1-O-acetylloloanolide B (54) (Fig. 4). [20,21] Otteliones, isolated from the freshwater plant Ottelia alismoides, ${ }^{[20]}$ display antitubercular activity and cytotoxicity at sub-nanomolar levels against a panel of 60 human cancer cell lines. Loloanolides ${ }^{[21]}$ have been isolated from the extract of aerial parts of Camchaya loloana, and exhibit cytotoxicity against the HepG2 cell line, with GI50 values at a nanomolar level. It is believed that the biological activity of these molecules may involve important interactions by the presence of a unique 4-methylene-2-cyclohexenone (50a) moiety.

Kaliappan's strategy for the synthesis of this unique 4-methylene-2-cyclo- hexenone moiety began with the known ketone 18, which was transformed into enyne alcohols 56a-d ${ }^{[19]}$ in a few steps. These on treatment with Grubbs' secondgeneration catalyst $\mathbf{2}$ underwent a smooth cross-enyne metathesis with ethylene gas and the resultant triene further underwent RCM to afford products 57a-d (Scheme 8 ). The resultant alcohols $\mathbf{5 7 a - d}$ were oxidized further to the required enones $\mathbf{5 5 a}-\mathbf{d}$ using Dess-Martin periodinane. After the construction of cis-fused 4-methylene2-cyclohexenone frameworks $\mathbf{5 5 a}-\mathbf{d}$, this strategy was extended for the synthesis of trans-fused scaffold $\mathbf{6 0}$ as outlined in Scheme 9. ${ }^{[19]}$ Thus, a simple and efficient strategy for the construction of the 4-methylene-2-cyclohexenone framework using a tandem enyne/RCM sequence has been achieved via domino metathesis. This strategy has potential to synthesize a large library of compounds required for biological screenings.

Recently, Kotha et al. reported the use of tandem cross-enyne/RCM strategy for the synthesis of macrocyclic alpha amino acid (AAA) derivatives. ${ }^{[22]}$ Macrocyclic peptides exhibit increased affinity to a given biological receptor with diminished sensitivity to cellular peptidases. Their synthetic strategy began with a known 2-acetamido-3-ethoxy-3-oxopropanoic acid (61), which was easily converted into an enyne 62. This enyne 62 under-

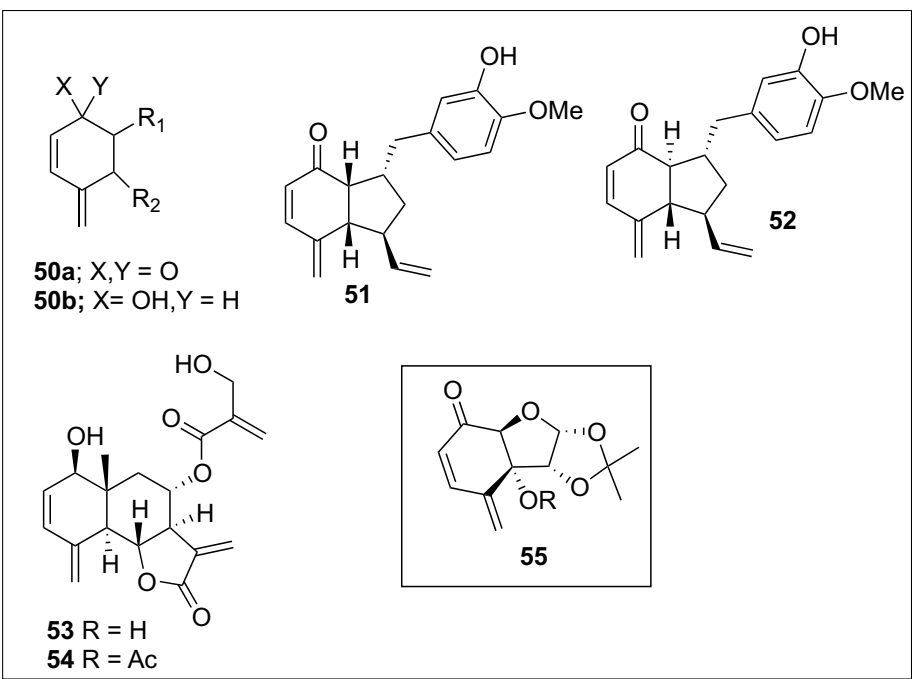

Fig. 4. Structures of otteliones $A$ (51) and $B(52)$, loloanolide $B(53)$ and 1-O-acetylloloanolide $B$ (54) and the proposed 4-methylene2-cyclohexenone derivative 55 . 

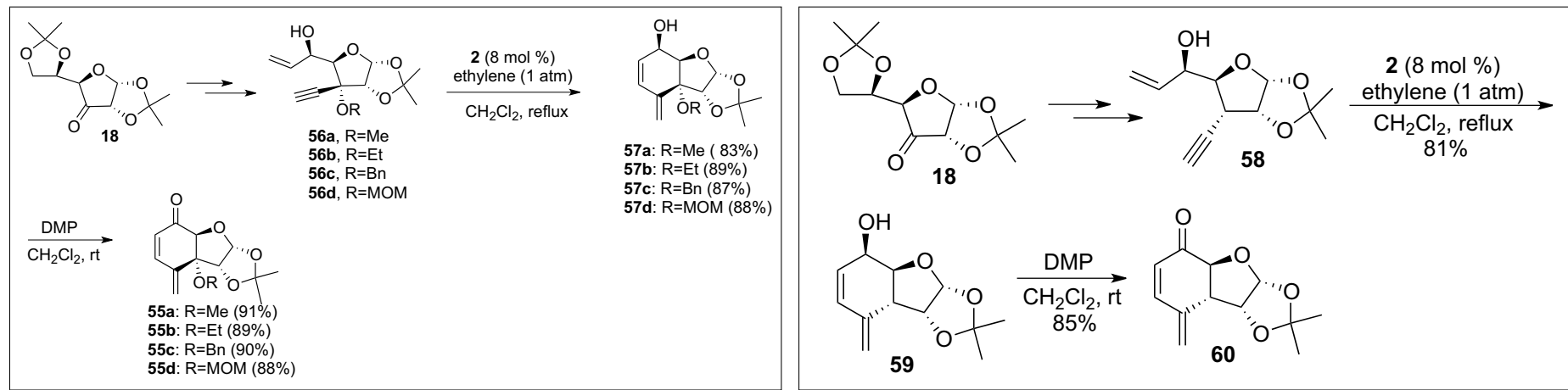

Scheme 8. Synthesis of 4-methylene-2-cyclohexenone frameworks 55a-d. Scheme 9. Synthesis of 4-methylene-2-cyclohexenone frameworks 60.

went cross-enyne metathesis reaction with 1,5-hexadiene to afford a mixture of $Z$ - and $E$-isomers (64 and 65). The Z-isomer 64 spontaneously cyclized further through $\mathrm{RCM}$ to form the required macrocyclic AAA 66, while the $E$-isomer $\mathbf{6 5}$ remained uncyclized (Scheme 10). However, the use of more reactive Hoveyda-Grubbs' firstgeneration catalyst 63 exclusively gave the required macrocycle 66 in excellent yield, and formation of any uncyclized product was not observed (HPLC). Fluorescent properties of these macrocycles were studied, and the fluorescence behavior suggests that their potential applications in biological sciences as biomarkers, ion sensors and peptidomimetics. ${ }^{[22]}$ They had earlier utilized this cascade sequence in synthesis of novel macro-heterocyclic rings of varied size (13-16).[23]

\section{Domino ROM/RCM Reaction}

The generation of two new terminal alkenes by ROM and subsequent cyclization of these two alkenes with other alkenes via a RCM in the same pot is another fascinating cascade protocol. In 2002, Mehta et al., in their attempts to synthesize the $\mathrm{AB}$ ring of paclitaxel (taxol, 68) ${ }^{[24]}$ using RCM reaction, serendipitously observed ${ }^{[25]}$ the formation of interesting products obtained by a domino ROM/RCM reactions (Scheme 11). Attempted RCM reaction on trieneone 71 did not lead to the required bicyclic product $\mathbf{7 2}$ and hence this reaction was attempted on its precursor 70. Surprisingly, the substrate $\mathbf{7 0}$ underwent ROM, which further formed two five-membered rings by $\mathrm{RCM}$ reactions with the preinstalled terminal alkenes. The alcohol $\mathbf{7 3}$ further underwent a facile allylic rearrangement to form alcohol 74. This strategy has been successfully extended to the homologues of precursor 70, to produce corresponding domino ROM/ RCM products.

Srikrishna etal. elegantly used this domino ROM/RCM strategy in the synthesis of elisabethin diterpenes. ${ }^{[26]}$ Elisabethain A (76, Scheme 12), a diterpene, isolated from $P$. elisabethae, exhibits interesting

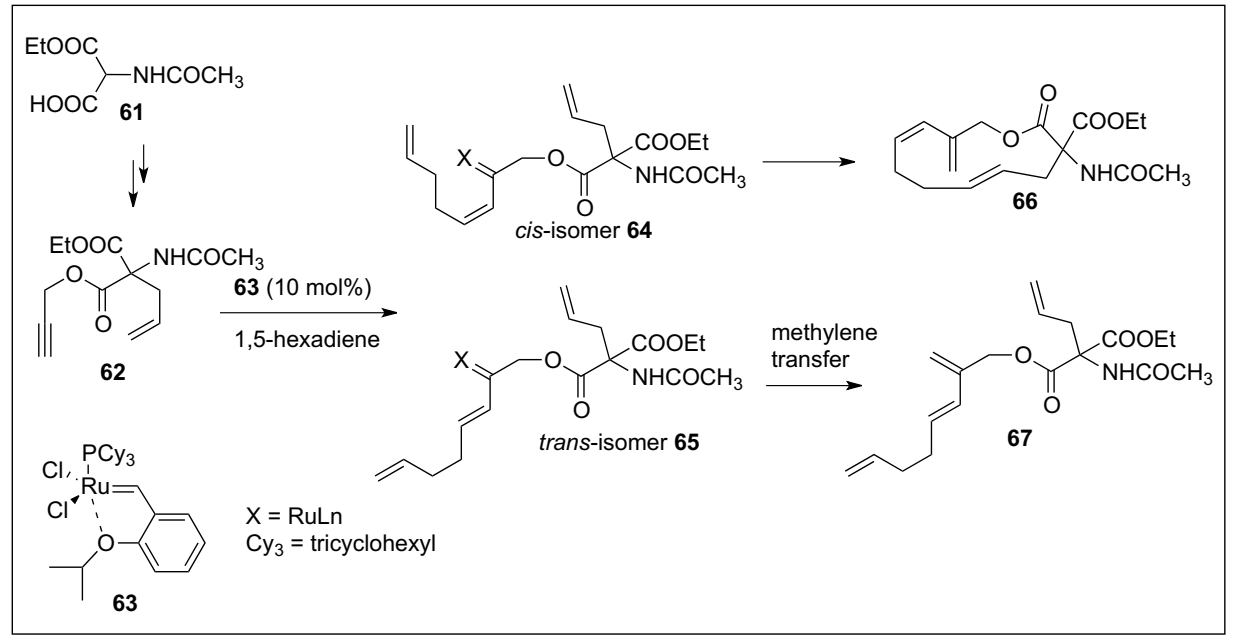

Scheme 10. Synthesis of macrocyclic AAA.

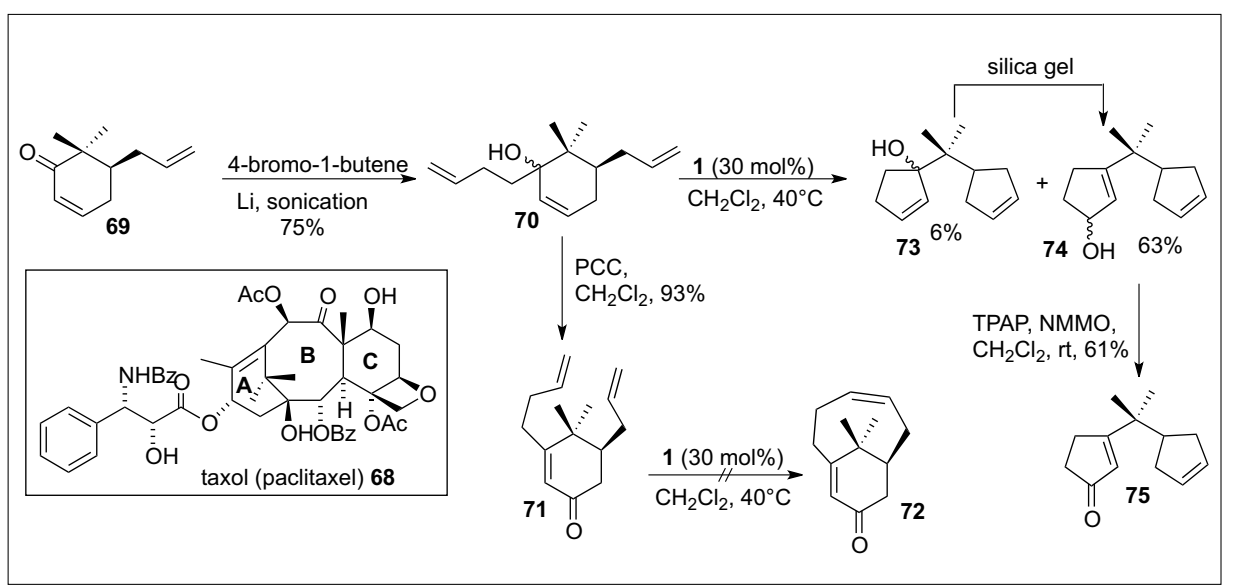

Scheme 11. Tandem ROM/RCM by Mehta et al.

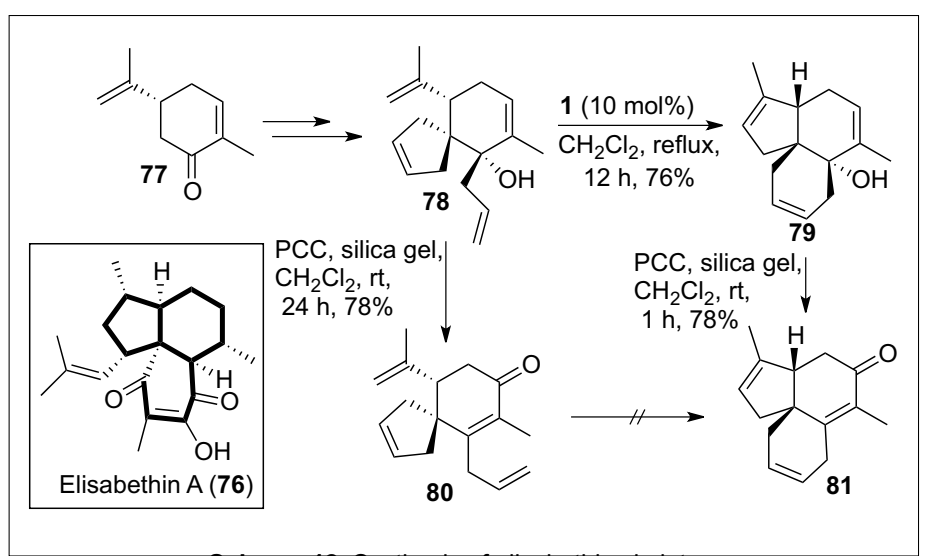

Scheme 12. Synthesis of elisabethin skeleton. 


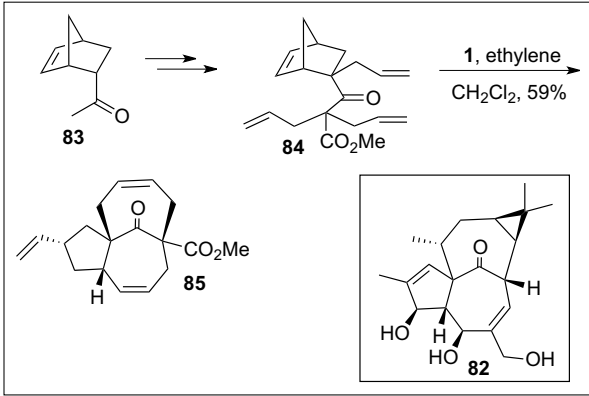

Scheme 13. Norbernene-based ROM/RCM strategy.

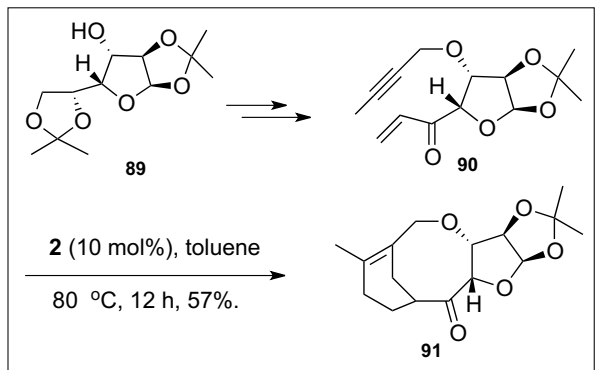

Scheme 15. Synthesis of taxa-oxa-sugar hybrid structure 91 .

anti-inflammatory, antibacterial, analgesic and cytotoxic activities. The spiro cyclopentene moiety in $\mathbf{7 8}$, readily prepared from carvone in a few steps, served as a masked gem-diallyl group. Thus, alcohol $\mathbf{7 8}$ on treatment with Grubbs' catalyst $\mathbf{1}$ in refluxing $\mathrm{CH}_{2} \mathrm{Cl}_{2}$ readily formed the $\mathrm{ROM}$ / RCM product 79. This was further transformed into enone 81, which formed the key tricyclic core structure of elisabethin diterpenes. However, this ROM/RCM reaction did not proceed when oxidation of allylic tertiary alcohol was carried out first and the tandem reaction $\mathrm{ROM} / \mathrm{RCM}$ reaction was subsequently attempted.

Norbornenes are the most popular substrates for cascade ROM/RCM reactions. ${ }^{[27]}$ In 2007, Ghosh and co-workers reported the efficient use of domino ROM/RCM strategy for the synthesis of the core structure of ingenol (82) (Scheme 13). ${ }^{[28]}$ Ingenol is a tetracyclic diterpene, which shows interesting anti-cancer and antiHIV properties. Norbernene-derived ketone $\mathbf{8 3}$ on treatment with catalyst $\mathbf{1}$ under ethylene atmosphere furnished the tricyclo-[7.4.1.0 $0^{1,5}$ ]tetradecene skeleton $\mathbf{8 5}$. The group has also elegantly extended this norbernene-based ROM/RCM strategy for the construction of several complex cyclic core structures found in many natural products. ${ }^{[29]}$

\section{Tandem Enyne/Diels-Alder Reaction}

A metathesis reaction followed by a non-metathetic process in sequential fash-

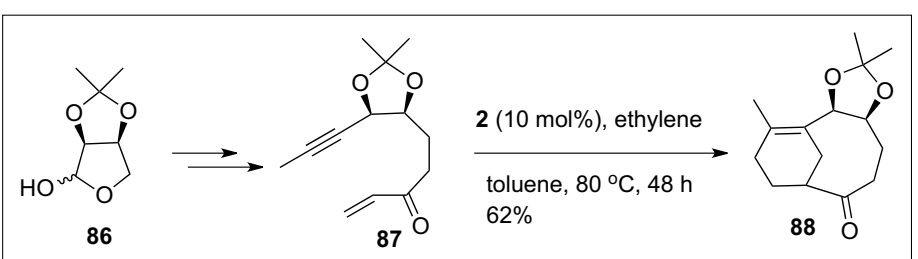

Scheme 14

Synthesis of bicyclo[5.3.1] undecene (88).

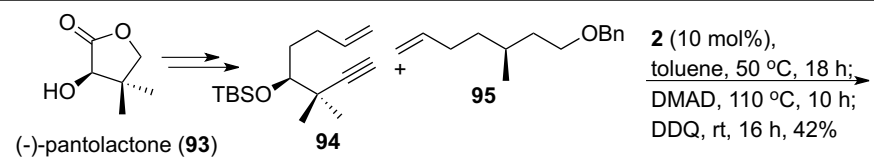

Scheme 16. Total synthesis of isofregenedadiol (92).

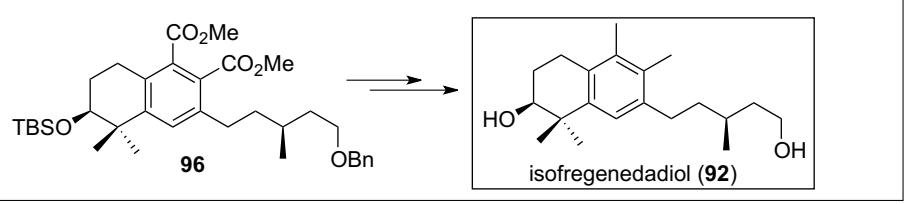

ion has also gained a lot of attention in organic synthesis. ${ }^{[30]}$ Enyne metathesis can efficiently generate 1,3-dienes, which are starting materials for the Diels-Alder reaction. A domino process is feasible between 1,3-diene generated by an enyne reaction and a dienophile present in the substrate. This would lead to intramolecular DielsAlder reaction (IMDA), and thus a domino cross-metathesis/IMDA has a potential to generate a variety of cyclic systems.

Kaliappan et al. have reported the construction of a bicyclo[5.3.1] undecene system by a tandem cross-enyne metathesis/ IMDA.[31] The enyne 87, synthesized from lactol 86 (Scheme 14) was subjected to a domino cross-enyne metathesis with ethylene and IMDA with Grubbs' catalyst $\mathbf{2}$ in toluene to afford bicyclo[5.3.1] undecene 88. ${ }^{[31]}$

After synthesizing the AB-ring skeleton of taxol, the same group extended this domino strategy for the synthesis of taxaoxa-sugar hybrid. The aim was to develop simpler analogues of taxol by synthesizing hybrid structures of taxol and screen them for biological activity. ${ }^{[32]}$ The core structure of taxa-oxa-sugar hybrid was synthesized starting from diacetone-D-glucose 89, which was transformed into enone $\mathbf{9 0}$ (Scheme 15) in a few steps. The tandem reaction was subsequently carried out with Grubbs' second generation catalyst 2 under ethylene atmosphere in toluene ${ }^{[32]}$ to afford the tricyclic compound $\mathbf{9 1}$ in good yield.

In 2011, Reddy and co-workers reported the first total synthesis of isofregenedadiol (92), ${ }^{[33]}$ using a domino enyne, cross metathesis and Diels-Alder reaction as a key step. Isofregenedadiol (92) is a tetrahydronaphthalenic diterpenic diol isolated from Halium viscosum. The required enyne substrate 94 was synthesized from (-)-pantolactone 93, and the alkene 95 was readily made from (-)-citronellol in a few steps. In this one-pot quadruple sequence, the enyne precursor 94 underwent initially an intramolecular enyne metathesis to form a 1,3-diene, that further underwent a cross-metathesis with alkene 95 (Scheme 16). The resultant diene on heating with dimethylacetylenedicarboxylate (DMAD) smoothly formed the Diels-Alder product, which on treatment with DDQ aromatized to form 96. This product was further elaborated to the target molecule $\mathbf{9 2}$.

\section{Summary and Outlook}

In summary, in the last couple of decades, synthetic chemists from India have been actively involved in using rutheniumcarbene catalyzed metathesis reactions for the syntheses of several complex natural products and natural product like molecules. This review has discussed only selected one-pot domino metathesis reactions. Such domino forms of this reaction have been utilized to synthesize several polycyclic systems, which mimic many biologically important natural products. Efficient construction of cyclic systems is a key to shorten total synthesis of complex architecture and secure access to a variety of analogues helpful for biological screenings. Importantly, many domino reactions reported in this review used inexpensive, optically pure and commercially available chiral starting materials. Research in this area will continue to attract more attention from synthetic chemists in their quest to efficiently synthesize biologically active complex natural products and new molecular scaffolds.

Received: October 7, 2012

[1] (a) P. Schwab, M. B. France, J. W. Ziller, R. H. Grubbs, Angew. Chem., Int. Ed. Engl. 1995, 34, 2039; (b) P. Schwab, R. H. Grubbs, J. W. Ziller, J. Am. Chem. Soc. 1996, 118, 100; (c) E. L. Dias, S. T. Nguyen, R. H. Grubbs, J. Am. Chem. Soc. 1997, 119, 3887; (d) M. Scholl, S. Ding, C. W. Lee, R. H. Grubbs, Org. Lett. 1999, 1, 953. 
[2] (a) S. B. Garber, J. S. Kingsbury, B. L. Gray, A. H. Hoveyda, J. Am. Chem. Soc. 2000, 122, 8168; (b) K. Grela, S. Harutyunyan, A. Michrowska, Angew. Chem., Int. Ed. Engl. 2002, 41, 4038; (c) R. Bujok, M. Bieniek, M. Masnyk, A. Michrowska, A. Sarosiek, H. Stepowska, D. Arlt, K. Grela, J. Org. Chem. 2004, 69, 6894.

[3] For reviews on enyne metathesis, see: (a) M. Mori, in 'Enyne Metathesis' in Top. Organomet. Chem. Ed. A. Fürstner, Springer, Berlin Heidelberg, 1998; 1, 133; (b) C. S. Poulsen, R. Madsen, Synthesis 2003, 1; (c) S. T. Diver, A. J. Giessert, Chem. Rev. 2004, 104, 1317; (d) S. V. Maifeld, D. Lee, Chem. Eur. J. 2005, 11, 6118.

[4] For reviews on the RCM reaction, see: (a) M. Schuster, S. Blechert, Angew. Chem., Int. Ed. Engl. 1997, 36, 2036; (b) 'Alkene Metathesis in Organic Synthesis', Ed. A. Fürstner, Springer, Berlin, 1998; (c) S. K. Armstrong, J. Chem. Soc., Perkin Trans. 1 1998, 371; (d) R. H. Grubbs, S. Chang, Tetrahedron 1998, 54, 4413; (e) A. J. Phillips, A. D. Abell, Aldrichim. Acta 1999, 32, 75; (f) D. L. Wright, Curr. Org. Chem. 1999, 3, 211; (g) A. Fürstner, Angew. Chem. Int. Ed. 2000, 39, 3012; (h) R. Roy, S. Das, Chem. Commun. 2000, 519; (i) M E. Maier, Angew. Chem., Int. Ed. Engl. 2000, 39, 2073; (j) M. Jorgensen, P. Hadwiger, R. Madsen, A. E. Stutz, T. M. Wrodnigg, Curr. Org. Chem. 2000, 4, 565; (k) T. M. Trnka, R. H. Grubbs, Acc. Chem. Res. 2001, 34, 18; (1) S. Kotha, N. Sreenivasachary, Ind. J. Chem. 2001, 40(B), 763; (m) M. A. Walters, Progress in Heterocyclic Chemistry 2003, 15, 1; (n) S J. Connon, S. Blechert, Angew. Chem., Int. Ed. Engl. 2003, 42, 1900; (o) A. H. Hoveyda, R. R. Schrock, Comprehensive Asymmetric Catalysis, Supplement 2004, 1, 207; (p) M. Mori, J. Mol. Cat. A: Chemical 2004, 213, 73; (q) M. D. McReynolds, J. M. Dougherty, P. R. Hanson, Chem. Rev. 2004, 104, 2239; (r) A. Deiters, S. F. Martin, Chem. Rev. 2004, 104, 2199; (s) R. H. Grubbs, Tetrahedron 2004, 60, 7117;. (t) D. J. Wallace, Angew. Chem., Int. Ed. Engl. 2005, 44, 1912. (u) K. C. Nicolaou, P. G. Bulger, D. Sarlah, Angew. Chem., Int. Ed. Engl. 2005, 44,
4490; (v) Special Issue: 'Olefin Metathesis', Ed. R. H. Grubbs, R. R. Schrock, A. Fürstner, Adv. Synth. Catal. 2007, 359, 1; (w) K. Grela, Angew. Chem. Int. Ed. 2008, 47, 5504.

[5] For reviews on tandem metathesis: (a) F.-D. Boyer, I. Hanna, Eur. J. Org. Chem. 2006, 471; (b) S. Kotha, M. Meshram, A. Tiwari, Chem. Soc. Rev. 2009, 38, 2065; (c) J. C. Lopez, J. Plumet, Eur. J. Org. Chem. 2011, 1803; (d) J. Li, D. Lee, Eur. J. Org. Chem. 2011, 4269; (e) N. Holub, S. Blechert, Chem. Asian J. 2007, 2, 1064; (f) M. C. Haibach, S. Kundu, M. Brookhart, A. S. Goldman, Acc. Chem. Res. 2012, 45, 947.

[6] K. P. Kaliappan, Lett. Org. Chem. 2005, 2, 678.

[7] K. P. Kaliappan, R. S. Nandurdikar, Chem. Commun. 2004, 40, 2506.

[8] (a) I. Kouno, K. Mori, N. Kawano, S. Sato, Tetrahedron Lett. 1989, 30, 7451; (b) I. Kouno, K. Mori, S. Okamoto, S. Sato, Chem. Pharm. Bull. 1990, 38, 3060. For synthetic studies, see: (c) B.-C. Hong, Y.-J. Shr, J.-L. Wu, A. K. Gupta, K.-L. Lin, Org. Lett. 2002, 4, 2249.

[9] (a) J.-M. Huang, R. Yokoyama, C.-S. Yang, Y. Fukuyama, Tetrahedron Lett. 2000, 41, 6111; (b) J.-M. Huang, C.-S. Yang, M. Tanaka, Y. Fukuyama, Tetrahedron 2001, 41, 4691.

[10] A. F. Krasso, M. Binder, C. Tamm, Helv. Chim. Acta 1972, 55, 1352.

[11] G. R. Pettit, T. R. Kasturi, J. C. Knight, J. Org. Chem. 1970, 35, 1404.

[12] K. P. Kaliappan, R. S. Nandurdikar, M. M. Shaikh, Tetrahedron 2006, 62, 5064.

[13] K. P. Kaliappan, R. S. Nandurdikar, Org. Biomol. Chem. 2005, 3, 3613.

[14] (a) J. D. Connolly, R. A. Hill, 'Dictionary of Terpenoids', Chapman and Hall, London, 1991, Vol. 1, 476; (b) N. H. Fischer, E. J. Olivier, H. D. Fischer, in Fortschr. Chem. Org. Naturst., Ed. W. Herz, H. Grisebach, G. W. Kirby, Springerverlag, New York, 1979, Vol. 38, 47.

[15] S. B. Christensen, A. Andersen, U. W. Smitt, Fortschr. Chem. Org. Naturst. 1997, Vol. 71, 129 and references therein.

[16] J.-Y. Ma, Z.-T. Wang, L.-S. Xu, G.-J. Xu, Phytochemistry 1999, 50, 113.
[17] H.-F. Wong, G. D. Brown, J. Nat. Prod. 2002, $65,481$.

[18] P. R. Krishna, M. Narsingam, Tetrahedron Lett. 2007, 48, 8721 .

[19] V. V. Betkekar, S. Panda, K. P. Kaliappan, Org. Lett. 2012, 14, 198.

[20] S. E. N. Ayyad, A. S. Judd, W. T. Shier, T. R. Hoye, J. Org. Chem. 1998, 63, 8102.

[21] C. S. Li, H. W. Yu, X. Z. Chen, X. Q. Wu, G. Y. Li, G. L. Zhang, Helv. Chim. Acta 2011, 94, 105.

[22] S. Kotha, D. Bansal, K. Singh, S. Banerjee, J. Organomet. Chem. 2011, 1856.

[23] S. Kotha, K. Singh, Eur. J. Org. Chem. 2007, 5909.

[24] D. G. I. Kingston, Chem. Commun. 2001, 867.

[25] G. Mehta, J. Nandakumar, Tetrahedron Lett. 2002, 43, 699.

[26] A. Srikrishna, V. H. Pardeshi, G. Satyanarayana, Tetrahedron Lett. 2007, 48, 4087.

[27] (a) M. F. Schneider, N. Lucas, J. Velder, S. Blechert, Angew. Chem., Int. Ed. Engl. 1997, 36, 257; (b) O. Arjona, A. G. Csaky, J. Plumet, Eur. J. Org. Chem. 2003, 611; (c) G. M. Weeresakare, Z. Liu, J. D. Rainer, Org. Lett. 2004, 6, 1625; (d) Z. Liu, J. D. Rainer, Org. Lett. 2005, 7, 131.

[28] C. K. Malik, S. Ghosh, Org. Lett. 2007, 9, 2537.

[29] (a) S. Maity, S. Ghosh, Tetrahedron Lett. 2008, 49, 1133; (b) S. Mondal, C. K. Malik, S. Ghosh, Tetrahedron Lett. 2008, 49, 5649; (c) C. K. Malik, R. N. Yadav, M. G. B. Drew, S. Ghosh, J. Org. Chem. 2009, 74, 1957; (d) K. Matcha, S. Maity, C. K. Malik, S. Ghosh, Tetrahedron Lett. 2010, 51, 2754; (e) S. Bose, M. Ghosh, S. Ghosh, J. Org. Chem. 2012, 77, 6345.

[30] V. Dragutan, I. Dragutan, J. Organometallic Chem. 2006, 5129.

[31] K. P. Kaliappan, V. Ravikumar, S. A. Pujari, Tetrahedron Lett. 2006, 47, 981.

[32] R. S. Nandurdikar, A. V. Subrahmanyam, K. P. Kaliappan, Eur. J Org. Chem. 2010, 2788.

[33] S. E. Kurhade, A. I. Sanchawala, V. Ravikumar, D. Bhuniya, D. S. Reddy, Org. Lett. 2011, 13, 3690 . 